\title{
Susumu Ohno
}

Of the seventy years of his life, I have known Susumu Ohno for more than half. In the summer of 1962 , I paid a short visit to his laboratory in Duarte, California on the advice of Dr. Klaus Pätau of Madison, Wisconsin, where I was a postdoctoral fellow. Obviously Dr. Pätau already then considered Susumu as an authority in the rather young and growing field of human cytogenetics. Typically for Susumu, in the spring of 1963 he had already come to visit me in my new laboratory in Freiburg to encourage my first independent steps in cytogenetics. Since then up to the present, he has stopped by almost every year to present us with his current research and sweep us along with his contagious enthusiasm. It is no surprise that our discussions led to collaborations on various topics, and in retrospect I feel privileged that my scientific interests were shaped to a considerable degree by such a comprehensively thinking person.

Susumu Ohno was born Japanese in Seoul, Korea on February 1st, 1928 as the 2nd of 5 children. He once told me that one of his brothers became a well-known writer in Japan. Thus, with this family connection, it is not surprising that Susumu's books are so brilliantly written. His father was a civil governor at that time, and the family returned to Japan after the war in 1945. From the miserable war and post-war period Susumu retained his dislike for potatoes and became a most refined gourmet (he acquired the habit of visiting us in May, which is the asparagus season in Freiburg). It may not be too far from the truth that he even chose his research animals, ranging from fish to mammals, according to their culinary attributes. His penchant for horses prompted him to study veterinary science, and I guess horses accompanied him all his life. His passion focused on thoroughbred horses, and he and his family always keep at least two of them at home. It is only to be expected that he pursued this extramural activity to perfection, winning many prizes in the haute école of riding. Fig. 1 shows his horse Kolman illustrating at the same time Susumu's highly gifted talent of drawing.

He received his doctor's degree of veterinary science at Tokyo University of Agriculture and Technology in 1949. Later on, he also acquired the degrees of Ph.D. in 1956 and D.Sc. in 1961, both at Hokkaido University.

Susumu married Midori Aoyama in 1951, and they have two sons and one daughter. I had the pleasure to meet this wonderful family not only in their most hospitable home, but also during a longer sojourn in Basel. Our families came into closer contact and they found common interests, e.g. in music, however, I didn't foresee that Susumu would eventually produce musical scores based on gene DNA sequences, to be performed by Midori at the piano.

Susumu went to the United States in the summer of 1952 as an official exchange visitor, sent to U.C.L.A. by the Institute for Infections and Disease of Tokyo University where he was a junior research fellow. At that time, the then unknown City of Hope Medical Center started a research department, and his U.C.L.A. professor, Dr. Carpenter thought that the work at City of Hope might be more beneficial to him. The first director at the newly founded Research Institute was Dr. Riojun Kinosita, well known for his cancer research work, who became a mentor and close friend of Susumu. Apart from some visiting professorships at places such as the Albert Einstein College of Medicine in the Bronx, New York and the Basel Institute of Immunology, Susumu remained at the City of Hope where he found the freedom for his work. After starting at the City of Hope as a research associate, he became senior research scientist, then director of the Division of Biology, and finally from 1981 onwards, he was honored with the Ben Horowitz Chair of Distinguished Scientist in Theoretical Biology. He belongs to the Board of Directors of the Beckman Research Institute of 


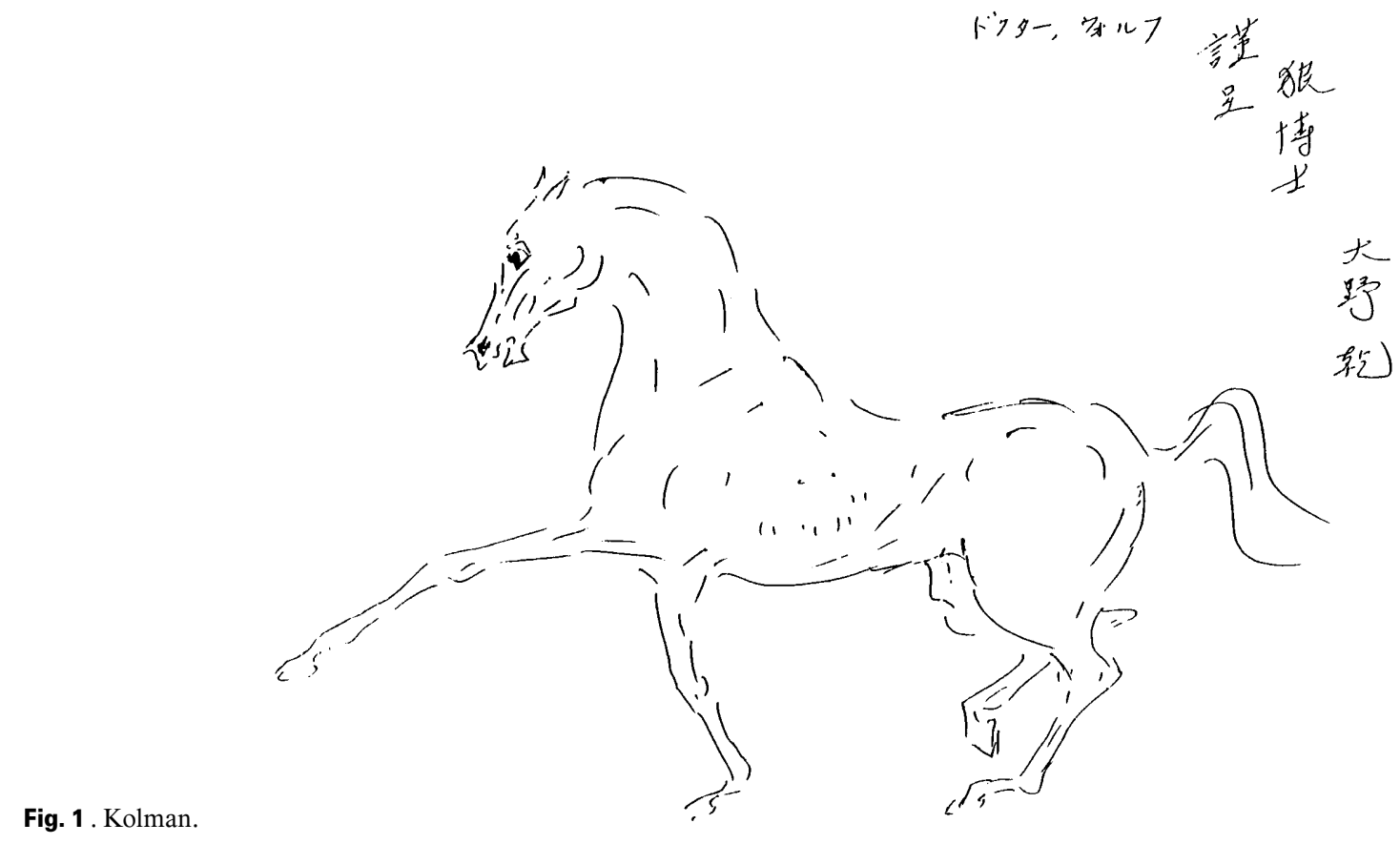

the City of Hope. In 1981, he was also elected a member of the U.S. Academy of Sciences. He is a member of other scientific societies and academies in the U.S. and abroad, and has served on various committees and editorial boards. Among the numerous honors and awards he has received, I mention only the doctor honoris causa awarded to him by the University of Pennsylvania. In addition to his engagement in Duarte, he was appointed to a professorship at Tohoku University, and therefore regularly spends some time in Japan. As an emeritus since 1996, he has shifted his working place to his home, but still keeps an office at the City of Hope.

Already during my early contacts with Susumu, I learned that he had carefully studied the strategies of famous field marshals and the plans of historical battles from Alexander the Great to the Prussian von Moltke. He felt that in an abstract sense these strategies would provide models for scientific thinking, and indeed, Susumu liked it very much to perform intellectual exercises which he called "gedanken experiments" (Differentiation 17, p. 14, acknowledgements, 1980), and there are numerous examples of these in essays, e.g. about intelligence and behavior, foresight and hindsight in evolution, the genetics of aging, and in particular about the implications of the repetitious recurrence of certain DNA sequence motifs.

His research activities can roughly be divided into an earlier more experimental and a later more theoretical period. When he passed into the fourth decade of his life, he once told me that physically, his older son would then begin to outmatch him e.g. in horse riding competitions, but intellectually, life would become much more satisfying. This period of his life indeed marks his changing devotion from narrower studies predominantly in experimental cytogenetics, to more general problems of biology including mechanisms of evolution, development and cell differentiation. Of his comprehensive scientific oeuvre, I will highlight only a few selected findings, conclusions and ideas which can be regarded to have entered history of biological thought.

Around 1960, Susumu's studies on sex chromatin prepared the basis for the Lyon hypothesis. He demonstrated the single-X nature of sex chromatin in various mammalian species including man and he interpreted sex chromatin as the morphological expression of functional allocycly. He also showed that in the female germ line, allocycly of one of the two $\mathrm{X}$ chromosomes does not occur and that during meiosis the $\mathrm{X}$ chromosomes behave exactly like autosomes and are not isolated from each other. His comprehensive study of human oogenesis together with H.P. Klinger and N.B. Atkin has become a classic. In the mid-sixties, two experimentally-based hypotheses with important phylogenetic implications were put forward by Susumu in collaboration with W. and M.L. Beçak. The finding of a roughly equal X-autosome ratio and a similar absolute size of the $\mathrm{X}$-chromosome in various mammalian species prompted him to postulate that the $\mathrm{X}$ chromosome was conserved during mammalian evolution, retaining the genetic constitution of a common 
ancestor. This hypothesis has been amply confirmed and has become known as "Ohno's law". The other far-reaching hypothesis refers to the origin and evolution of the sex chromosomes first evidenced in differently advanced snake families exhibiting homomorphic or increasingly heteromorphic sex chromosomes, respectively. This finding formed the basis for the assumption of an original pair of autosomes selected as the future sex chromosome pair, which by reduction of the chromosome determining the heterogametic sex, resulted in the small and highly specialized Y chromosome of mammals, a view which still holds.

All these findings are discussed and put into a wide biological perspective in his pioneering book of 1967 on "Sex Chromosomes and Sex-linked Genes".

During this period, Susumu presented his new discoveries regularly at the famous Basel Colloquium, and therefore, I feel that it should be mentioned in his biography. These meetings were initially organized by Harold Klinger and Marco Fraccaro, taking place from 1961 onwards at two-yearly intervals, and they were rather exclusive, gathering together the then most prominent researchers on the role and behavior of the sex chromosomes (later on the topics varied). When, on the recommendation of Susumu, I first was admitted to this elite group, I felt highly privileged.

Susumu extended his studies on genome size, which he had first applied to mammals, to the other vertebrate classes, leading him to the concept of evolution from fish to mammals by gene duplication. He provided evidence for polyploidization as an important early step during this evolutionary process, which can still be traced by comparison of genome sizes, gene number and ancestral gene homologies in some extant orders e.g. of teleostean fishes. He concluded that the human genome must also reflect early polyploidization events, which could indeed be shown, in addition to regionally limited gene duplications. These findings highlight the principle of the creation of new genes by duplication and subsequent divergence by mutation, thus allowing for the differentiation of a particular function or even the acquisition of a new function. This principle he presented as the motto on his symbolic drawing on the dust cover of his now classical book of 1970 on "Evolution by gene duplication", "amplius redundantiae-amplius mutationis". In his studies on genome evolution, Susumu also addressed the occurrence of satellite DNA for which he coined the term "junk DNA", now generally used in the literature. He discussed this phenomenon in his book of 1974 on "Protochordata, Cyclostomata and Pisces" which he kindly dedicated to me, under the aspect of "the importance of doing nothing".

Every now and then, Susumu was concerned with the problem of the origin and development of malignancy. It is interesting to read that he had already considered the transformation from a normal to a malignant somatic cell as a two- or multi-step process in 1971 in his review article "Genetic implication of karyological instability of malignant somatic cells" (Physiological Reviews 51, pp 496-526).

One of the central subjects of Susumu's interest remained the question of the genetic basis for the sex differences. In his view that increasing complexity in evolution is compensated for by simplification at the level of regulatory systems, he accentuated the need for master regulatory genes. For the manifestation of the sexual phenotype, the gene for the androgen receptor illustrates this principle in a convincing way. Looking for an appropriate gene on top of the sex-determining cascade, he came across H-Y antigen which appeared to be a good candidate at that time. His studies and ideas on this subject are laid down in his book of 1979 on "Major Sex-determining Genes" which still remains stimulating reading, although in the meantime the role of H-Y antigen has been replaced by SRY, at least in mammals.

In the years to follow, Susumu devoted himself more and more to problems in theoretical biology. He used the enormous expansion of knowledge about DNA sequences for deriving mechanisms and processes in sequence evolution, particularly with regard to universal principles. An idea favored by him is the principle of variations on the same theme, which follows from the immortality of the monophyletic germ line and the creation of new genes out of genes already present. His preferred molecules were those of the immune system that show repeat variation and periodicities of a building block that can be traced to cell adhesion molecules already present in organisms at the transition from uni- to multi-cellular organization. At the beginning of life, he envisages the first coding sequences as repeats of base oligomers, and using as an example a tetranucleotide repeat which was conserved during evolution, he showed (together with Jörg Epplen) that periodicity allows for the formation of secondary structures of the resulting product. Since repetitious recurrence governs so many manifestations of nature, Susumu attempted to transpose this principle to creations of human intellect using musical compositions as examples. Tempted by striking resemblances between musical motifs in compositions, e.g. by Chopin or J.S. Bach, and primordial coding sequences, Susumu together with his wife Midori devised an invariant rule for transforming coding sequences into musical scores and vice versa. In this way they composed scores of various molecules including phosphoglycerate kinase and RNA polymerase II, and they transcribed musical scores into base sequences giving long open reading frames. I tried several molecule-derived scores on my cello, and not surprisingly as the same principles are at work, it produced pleasant music. Depending on the conservation 
or progressive variation of the particular molecule, the character of the music corresponds to earlier or more modern periods of musical composition, respectively.

Susumu's theoretical endeavors in present years are wide-ranged, dealing with the question of intrinsic molecular mechanisms as opposed to selection, the role of palindromic sequences in molecular evolution, the problem of co-evolution, the origin of almost all extant animal phyla and the Cambrian explosion, patterns of ascendance of present day genomes, to mention just a few examples.

An overview of Susumu's scientific oeuvre reveals that he always was and still is tracing general rules governing biological processes, and indeed, he has put forward an impressive number of principles which have furthered our understanding of life. However, this appreciation would be incomplete without mentioning all his friends and colleagues whom he stimulated in sharp-witted discussions in the laboratory and relaxed conversations over a glass of wine.

For the years to come, I wish him further his indefatigable enthusiasm in all phenomena of life, and for myself many more encounters with him.

\section{Acknowledgement}

I am most grateful to Midori Ohno for kindly providing me with biographical hints.

Freiburg, Germany,

Ulrich Wolf

February, 1998 